\title{
SCIDOC
}

\author{
International Journal of Dentistry and Oral Science (IJDOS) \\ ISSN: 2377-8075
}

\section{Clinical Evaluation of Two Techniques for Narrow Alveolar Ridge Expansion: Clinical Study}

Research Article

Stepan Jarikian ${ }^{1}$, Mohamad Hassan Jaafo ${ }^{2}$, Zuhair Al-Nerabieah ${ }^{3 *}$

${ }^{1}$ Department of Oral and Maxillofacial Surgery, Faculty of Dentistry, Damascus University, Syria.

${ }^{2}$ Professor, Department of Oral and Maxillofacial Surgery, Faculty of Dentistry, Damascus University, Syria.

${ }^{3}$ Paediatric dentistry department, Dental collage, Damascus University, Al-Mazzeh St. Damascus, Syria.

\section{Abstract}

Background: Implant placement in horizontally deficient alveolar ridges can be challenging. Several Bone expanding surgical techniques have been established in order to simultaneously allow horizontal bone expansion along with implant placement in one surgical visit.

Aim/Hypothesis: To compare the amount of ridge expansion achieved using two different techniques, Osseodensification technique (ODT) and threaded expanders technique (TET).

Methods: Twenty-eight implant implants were inserted in 11 patients. Implants were divided into two equal distinct groups according to Ridge Expansion Technique: Osseodensification Technique (Group A) and Threaded Expander Technique (Group B). Alveolar ridge thickness was measured in two different stages (at the base line, after expansion and implant placement), and amount of alveolar ridge expansion in $\mathrm{mm}$ was calculated for each implant.

Results: Both techniques were useful in achieving expansion, and all implants placed were successful. The amount of achieved expansion was significantly higher in Osseodensification group where the average expansion was $2.36 \mathrm{~mm}$ while the average amount of expansion in threaded expanders group was $1.5 \mathrm{~mm}$.

Conclusions: The Osseodensification technique demonstrated the ability to increase ridge width and bone volume around implants without creating dehiscence or fenestration or sacrificing bone. This study showed that the amount of expansion achieved with Densah bur drilling was superior to manual threaded expanders.

Keywords: Osseodensification; Densah Burs; Threaded Expanders; Ridge Expansion.

\section{Introduction}

Bone resorption after tooth loss is inevitable event, often resulting in inadequate bone dimensions for dental implant placement in an ideal position [1]. After tooth extractionbucco-lingual alveolar ridge dimension decreases significantly, over a period of 3-12 months, the amount of resorption can reach approximately $50 \%$ of the original bone width [2]. Several Surgical techniques and reconstruction procedures have been proposed to increase alveolar ridge dimensionsin order to obtain sufficient bone volume for adequate implant placement [3-5].

These techniques include guided bone regeneration; bone block grafts; distraction osteogenesis; ridge splitting; ridge expansion; and combinations of techniques. Bone expansion is a technique used in atrophic alveolar ridges of about 3-4mm [6], the major benefit of this procedure is that the implants may be inserted simultaneously with the bone expansion procedure. The bone can beflexed to some extent due to its elasticity [7], compression and condensation of bone can be also achieved [8].

Summers in 1994 introduced the osteotome technique to compact and expand the bone and improve bone-implant interface properties [9]. It consists of a sequence of cylindrical bone condensing instruments, which compress the trabecular bone apically and laterally simultaneous to bone expansion. The goal of this technique is to increase implant primary stability and expand the edentulous ridge without removing additional bone $[9,10]$.

However, despite the benefits of the Summers' osteotome tech-

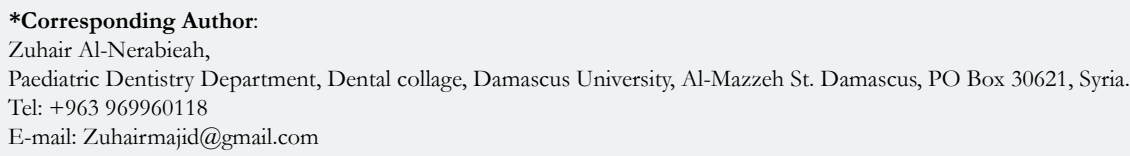

Received: December 09, 2020

Accepted: December 30, 2020

Published: January 09, 2021

Citation: Stepan Jarikian, Mohamad Hassan Jaafo, Zuhair Al-Nerabieah. Clinical Evaluation of Two Techniques for Narrow Alveolar Ridge Expansion: Clinical Study. Int J Dentistry Oral Sci. 2021;8(1):1337-1342. doi: http://dx.doi.org/10.19070/2377-8075-21000264

Copyright: Zuhair Al-Nerabieah ${ }^{\circ} 2021$. This is an open-access article distributed under the terms of the Creative Commons Attribution License, which permits unrestricted use, distribution and reproduction in any medium, provided the original author and source are credited. 
nique, there are limitations which include surgical trauma, unintentional fracture of bone, patient vertigo [11], and the use of osteotomes tend to induce micro-fractures of the trabeculae that may lead to prolonged healing period due to bone resorption, thus delaying osseointegration [12], and it is mainly designed for the maxilla.

A histologic study, noted that the increase in the bone density was only in the periapical area, while there was no significant change at the lateral walls [13].

Another technique has been introduced to improve the quality and quantity of bone around the implant, it consists of using threaded expanders that can facilitate width expansion of atrophic alveolar ridges without using a surgical mallet [14]. These expanders help to avoid the surgical trauma due to malleting [8], and permit a precise control on pressure exerted during ridge expansion. Moreover, itcanbe used as condensers of trabecular bone increasingbone density around the newly placed implant, thereby improving the primary stability [15].

This method of bone expansion is considered minimal invasive simple and useful technique to place implants in cases of horizontally absorbed ridges [16]. The threaded expander is different from the Summers' osteotome in design, technique of use and can be used in both the maxilla and mandible [17].

Recently,a new method of biomechanical bone preparation termed as Osseodensification was developed by Huwais [18]. It is carried out using specially designed burs named Densah. The burs are designed to preserve and compact bone, and can be used in the clockwise or counter-clockwise direction to increase the bone density and expand the osteotomy without the extraction of the bony matrix taking advantage of viscoelastic bone properties [19, 20], these burs combine advantages of osteotomes with the speed and tactile control of the drilling procedures and can be used for low and high density bones [21, 22].

According to the manufacturer, these special burs demonstrated the ability to expand narrow bone ridges similarly to split crest techniques [12].

The aim of this study is to compare the effects of Osseodensification burs and threaded expanders on bone expansion in narrow alveolar ridges.

\section{Materials and Methods}

The sample was consisted from 28 implants that were inserted to 11 subjects aging between 28 and 69 years old. Implants were divided into two equal distinct groups according to Alveolar Ridge Expansion Technique: Osseodensification Technique (ODT) and Threaded Expander Technique (TET).

\section{Patient selection}

The selection criteria of patients included patients of both genders, over 18 years who had a minimum of two missing teeth in either jaws with horizontally insufficient bony ridge for implant placement. All patients met the following inclusion criteria: good oral hygiene, presence of edentulous site with initial alveolar ridge width range between (4-5 $\mathrm{mm}$ ) with minimum of $2 \mathrm{~mm}$ trabecular bone core between cortical plates without buccal concavities. Patients were excluded if they had uncontrolled systemic conditions, or systemic disorders that could compromise osseointegration, or if they were taking medications that can affect bone metabolism such as steroids.

A cone beam computed tomography (CBCT) scan was carried out to patients before the intervention to asses bone quality and to quantify the ridge height and width of the supporting bone, and to locate major anatomical features.

The materials used consisted of Densah bur kit (Figure 1A), ACE threaded expanders kit (Figure 1B), TRI implant surgical kit, implant surgical motor and handpiece.

\section{Surgical procedure}

Preoperative antibiotics (1g of amoxicillin) were prescribed to each patient for 6 days, starting one hour before surgery. Local anesthesia was achieved by infiltrating lidocaine $2 \%$ containing 1:100000 adrenaline. A crestal incision was made without vertical incisions, and a full thickness mucoperiosteal flap was raised to gain access to the bone (Figure 2A). A small round bur was used to localize the sites where implants will be placed, and ridge thickness was recorded from the most coronal part of the alveolar ridge.

\section{Threaded Expanders Surgical Technique}

The ACE expansion kit composed of 4 Threaded bone expand-

Figure 1. (A) Universal Densah Bur Kit. (B) ACE Threaded Expanders Kit.

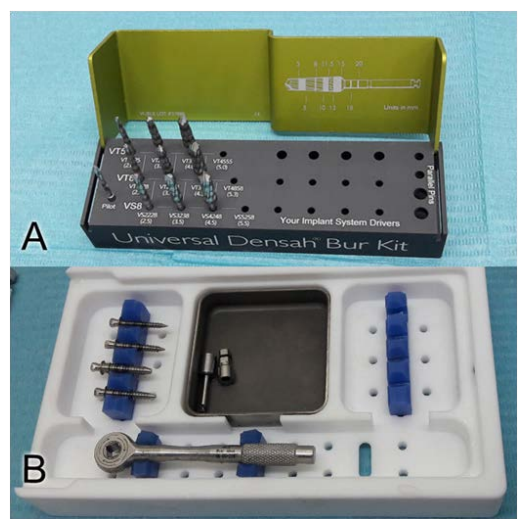


ers of increasing diameter, a carrier and a ratchet. Site preparation began with the use of a $1.7 \mathrm{~mm}$ pilot drill at speed of 1100 $\mathrm{rpm}$ to the desired depth. Once adequate depth was attained, a series of threaded expanders with progressively increasing diameter $(2.5,3.1,3.6) \mathrm{mm}$ were used to gradually expand the site horizontally, depending on bone width and the selected implant to be placed (Figure 2B). Expanders were always used carefully with hand control wrench, after each half turn, there was a pause of 10-20 seconds before turning the wrench another half turn in order to give time to bone to accommodate to the expansion. Finally, an implant was placed according to achieved expansion. The ridge width was then measured again at the top of the ridge.

\section{Osseodensification Surgical Technique}

The initial bone ridge width was measured after marking implant sites, then osteotomy was prepared to the desired depth using a $1.7 \mathrm{~mm}$ pilot drill (clockwise drilling at $1100 \mathrm{rpm}$ ) thereafter Densah Burs (Versah, LLC, Jackson, MI) were used (Figure 3A) in sequence, gradually wider diameter (2-2.3-3.3-3.5) $\mathrm{mm}$. The burs were used in a counterclockwise rotation and bouncing motion under profuse saline irrigation with speed of $1100 \mathrm{rpm}$ (Figure 3B). Each osteotomy was prepared to a diameter $0.2-0.5 \mathrm{~mm}$ less than the desired implant diameter.

\section{Implant Insertion}

Endosseous dental implants (TRI-Vent, Switzerland) were immediately placed after performing the bone expansion. All implants were installed without irrigation, using a low speed drilling procedure $(35 \mathrm{rpm})$.
After implant insertion, cover screws were secured, and the surgical wounds were closed by a non-resorbable 3-0 silk suture(Figure $4 \mathrm{~A}$ and $4 \mathrm{~B})$.

Following surgery, patients were encouraged to take, in case of pain, acetaminophen ( $1 \mathrm{~g} / 8$ hours). Another CBCT scan was taken to verify adequate placement of implants.

\section{Results}

Alveolar ridge thickness (in $\mathrm{mm}$ ) was measured in two different stages (before treatment, after finishing the osteotomy and implant placement) for each implant case in the sample (table 1). Alveolar ridge expansion (in $\mathrm{mm}$ ) was calculated for each implant in the sample like it is shown below:

Alveolar Ridge Expansion (in $\mathrm{mm}$ ) for each implant = Final Alveolar Ridge Thickness (in mm) - Initial Alveolar Ridge Thickness (in $\mathrm{mm}$ ) for the same studied implant.

Mean of alveolar ridge expansion values according to alveolar ridge expansion technique were $(2.36 \pm 0.31,1.50 \pm 0.28)$ in ODT and TET groups respectively (table 1 and figure 5). An Independent Samples t-test was applied to know if there were significant differences inalveolar ridge expansion(in $\mathrm{mm}$ ) values between ODT and TET groups. P-value was much lower than0.05, so, at the confidence level of $95 \%$ there were significant differences inalveolar ridge expansion (in $\mathrm{mm}$ ) between twogroupsin the studied Sample. Positive algebraic sign of mean difference indicates that alveolar ridge expansion (in $\mathrm{mm}$ ) value was greater in ODT group than in TET group.

Figure 2. (A) Full thickness mucoperiosteal flap elevation. (B) The threaded expanders used to expand the osteotomy.

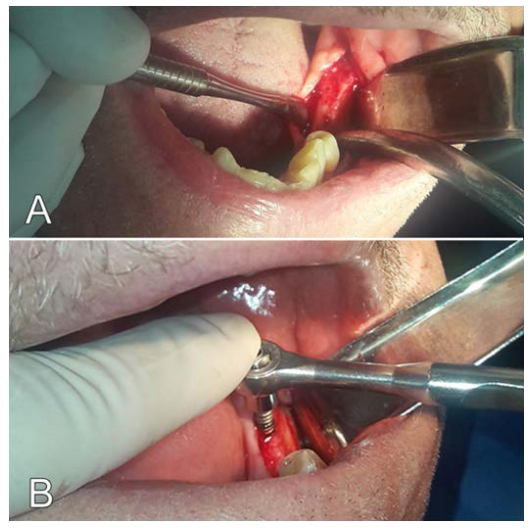

Figure 3. (A) Osseodensification Densah bur. (B) The Densah bur used to expand the osteotomy.

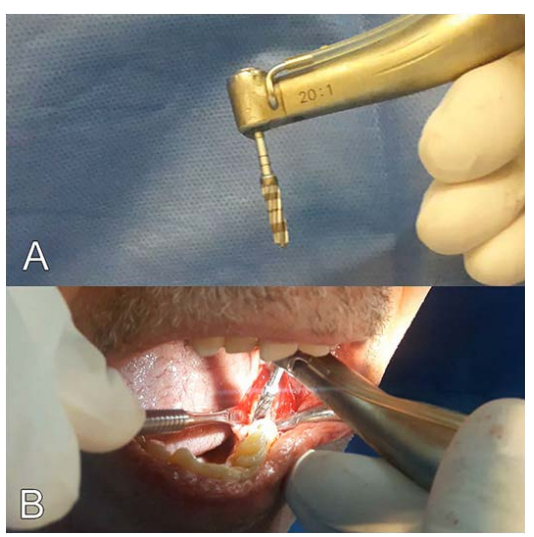


Figure 4. (A) Cover screws have been placed after implant placement. (B) Closure was made without tension.

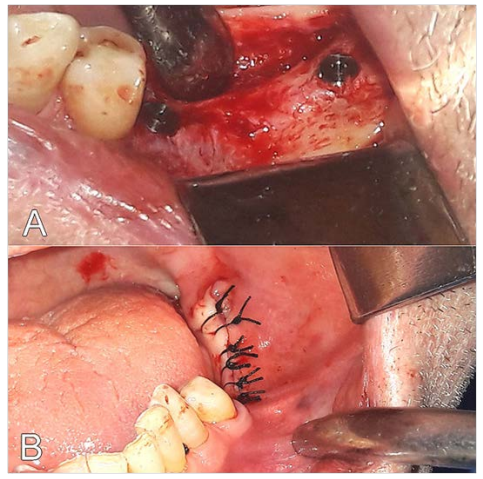

Figure 5. Mean of Alveolar Ridge Expansion (in mm) values according to Alveolar Ridge Expansion Technique.

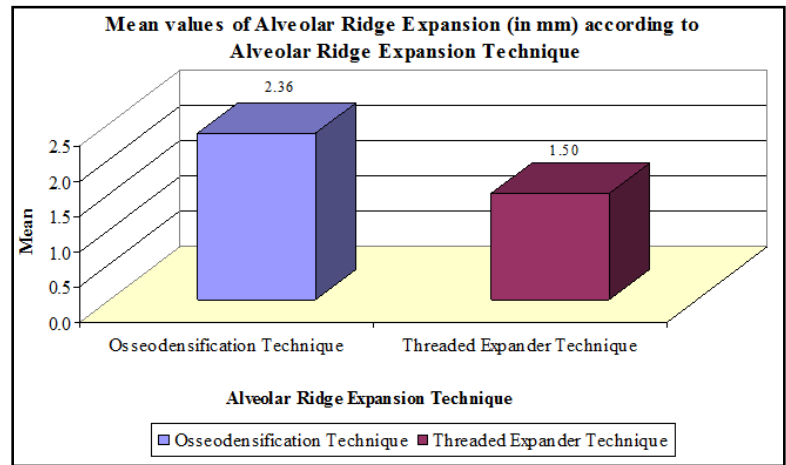

Table 1. Alveolar Ridge Expansion (in mm)descriptive statistics according to Alveolar Ridge Expansion Technique.

\begin{tabular}{|c|c|c|c|c|c|c|c|c|c|}
\hline \multicolumn{10}{|c|}{ Studied Variable $=$ Alveolar Ridge Expansion } \\
\hline $\begin{array}{l}\text { Alveolar Ridge } \\
\text { Expansion Tech- } \\
\text { nique }\end{array}$ & $\mathbf{N}$ & Mean & $\begin{array}{c}\text { Std. } \\
\text { Deviation }\end{array}$ & Std. Error & Minimum & Maximum & $\begin{array}{l}\text { Mean Dif- } \\
\text { ference }\end{array}$ & t-value & P-value \\
\hline $\begin{array}{c}\text { Osseodensification } \\
\text { Technique }\end{array}$ & 14 & 2.36 & 0.31 & 0.08 & 2 & 3 & \multirow{2}{*}{0.86} & \multirow{2}{*}{7.771} & \multirow{2}{*}{$0.000^{*}$} \\
\hline $\begin{array}{c}\text { Threaded Expand- } \\
\text { er Technique }\end{array}$ & 14 & 1.5 & 0.28 & 0.07 & 1 & 2 & & & \\
\hline
\end{tabular}

\section{Discussion}

The insufficient bone amount around implants could negatively influence the bone-implant contact, bone volume and consequently osseointegration. Several surgical techniques have been proposed to avoid or reduce bone sacrifice during implant placement. Summer's Osteotome technique is an alternative to implant drilling procedure that aimed to compact bone while expanding implant site, but it has drawbacks because it is considered a traumatic technique due to the need to repeatedly use the mallet. The modern ridge expansion instruments include motorized expanders, piezoelectric devices and Densah burs. This study investigated the effects of two bone expansion techniques on amount of expansion in narrow alveolar ridges, we chose to expand the ridges $>4 \mathrm{~mm}$ in order to avoid bone fractures which happens more frequently during expansion of narrow ridges of about $3 \mathrm{~mm}$. The results showed that both techniques were useful in achieving expansion depending on initial ridge width and bone quality. All placed implants in the two groups were successful at 6 months follow up period. The average amount of expansionin ODT group was significantly higher than the average expansion achieved in TET group. This could be explained by the special design of Densah bur that produce compression and compacts bone laterally during its counterclockwise rotation, this compression on the lateral walls of osteotomy creates plastic deformation allowing the ridge to expand taking advantage of viscoelastic bone properties. For TET group the lateral walls of the expanders contains several threads and the compression generated during expansion procedure becomes greater on the tips of the threads, which differs from Densah burs where the stress distributes evenly along the inner walls of the osteotomy. Moreover, Ridge expansion using threaded expanders is a sensitive surgical technique as the surgeon's experience plays an important role in controlling the procedure when using the manual expansion. The use of Osseodensification burs helps in decreasing the technique sensitive aspect of the expansion procedure. It is worth mentioning that more time is needed when using the threaded expanders as we had to wait 20 second between each half turn of the ratchet to give time and gradually expand bone, whereas this process is faster and automatically controlled by the surgical motor when using Densah burs, also the progressively increasing diameter of Densah burs helps in gradual expansion of the site as the bur enters in the osteotomy, and the use of these burs resulted in achieving safe ridge expansion within a short interval of time, causing 
minimal trauma. The role of Densah burs in improving insertion torque and primary implant stability has been studied by many authors [22-26], but the studies concerning the role of these burs in expanding narrow ridges are relatively few, and there are no available studies in literature where a comparison has been made between threaded expanders and Osseodensification technique. However, when evaluating Osseodensification technique Trisi and his colleagues in an in vivo study in sheep have shown that Densah burs allows the use of wider implants diameters in narrow alveolar ridges, with consequent increase in bone volume by 30\% [12]. Sletecompared three implant preparation methods, the results from his study demonstrated that osteotomy preparation using Osseodensification method resulted in significantly more bone volume surrounding the implant [27].

Our results agree with those reported by Gaspar who used ODT for implant site preparation in horizontally deficient ridges ranged between $(3.2-5.1 \mathrm{~mm})$, he found that the ridge expansion ranged from (1.1 to $2.4 \mathrm{~mm}$ ), and the greatest amount of bone expansion occurred at the coronal position, and was recorded on initially narrower ridges compared to wider ridges [28].

When evaluating TET, Mazzocco reported that the use of expanders is as effective as the lateral augmentation technique in increasing the thickness of horizontally deficient alveolar ridges [14].

Our results agree with those reported by Kim [16] who found that the use of threaded expanders is a successful and predictable technique for implant placement in narrow alveolar bone.

Chan evaluated the amount of ridge expansion achieved using screw expanders, the results of his study showed that the use of screw spreaders or expanders increased the ridge width by an average of $0.79 \mathrm{~mm}$ [29], these results were slightly different from our study, which may be explained that all the expanded sites in his study were in maxilla, and the amount of available cancellous bone between cortical plates influences the amount of expansion as the cancellous bone absorbs some pressure and results in bone compaction instead of expansion, thus reducing the effectiveness of the expander.

Our results came in agreement with the findings of Kao [30] who compared the ridge splitting and ridge expansion technique using expanders, the results showed that there was no statistically significant difference in crestal width gain between the two groups and the average width gain in ridge expansion group was $1.92 \pm$ $0.61 \mathrm{~mm}$.

Cortes in an analysis of 21 cases used threaded expanders to augment horizontally deficient ridges of about 3 to $5 \mathrm{~mm}$, all placed implants had successful osseointegration and the average ridge width gain was $2.5 \mathrm{~mm}$ [31], which was higher than what was achieved in our study.

\section{Conclusion}

Osseodensification technique is a safe and predictable way to expand narrow alveolar ridges without causing bone dehiscences or fenestrations, this technique preserves bone tissue and helps in improving bone volume and maintaining alveolar ridge integ- rity thereby allows simultaneous implants placement with superior stability. This study showed that the amount of expansion achieved with Densah bur drilling was superior to manual threaded expanders.

\section{Acknowledgment}

This research was funded by Damascus University.

\section{References}

[1]. Milinkovic I, Cordaro L. Are there specific indications for the different alveolar bone augmentation procedures for implant placement? A systematic review. Int J Oral Maxillofac Surg. 2014 May;43(5):606-25. Pubmed PMID: 24451333.

[2]. Schropp L, Wenzel A, Kostopoulos L, Karring T. Bone healing and soft tissue contour changes following single-tooth extraction: a clinical and radiographic 12-month prospective study. Int J Periodontics Restorative Dent. 2003 Aug;23(4):313-23.Pubmed PMID: 12956475.

[3]. Chiapasco M, Casentini P, Zaniboni M. Bone augmentation procedures in implant dentistry. Int J Oral Maxillofac Implants. 2009;24 Suppl:237-59. Pubmed PMID: 19885448.

[4]. Jensen SS, Terheyden H. Bone augmentation procedures in localized defects in the alveolar ridge: clinical results with different bone grafts and bonesubstitute materials. InDatabase of Abstracts of Reviews of Effects (DARE): Quality-Assessed Reviews [Internet] 2009. Centre for Reviews and Dissemination (UK).

[5]. Aghaloo TL, Moy PK. Which hard tissue augmentation techniques are the most successful in furnishing bony support for implant placement? Int J Oral Maxillofac Implants. 2007;22 Suppl:49-70. Erratum in: Int J Oral Maxillofac Implants. 2008 Jan-Feb;23(1):56.Pubmed PMID: 18437791.

[6]. Rodríguez JG, Ortuño EF, Marín BG, Erhardt MC. CONCEPT UPDATING: THE NEW TECHNOLOGIES, A THREE-DIMENSIONAL REDEFINITION IN IMPLANT SUPPORTED REHABILITATION.

[7]. Scipioni A, Bruschi GB, Calesini G, Bruschi E, De Martino C. Bone regeneration in the edentulous ridge expansion technique: histologic and ultrastructural study of 20 clinical cases. Int J Periodontics Restorative Dent. 1999 Jun;19(3):269-77. Pubmed PMID: 10635173.

[8]. Brugnami F, Caiazzo A, Mehra P. Piezosurgery-assisted, flapless split crest surgery for implant site preparation. J Maxillofac Oral Surg. 2014 Mar;13(1):67-72. doi: 10.1007/s12663-012-0377-3. Epub 2012 May 16.Pubmed PMID: 24644400.

[9]. Summers RB. A new concept in maxillary implant surgery: the osteotome technique. Compendium (Newtown, Pa.). 1994 Feb 1;15(2):152-4.

[10]. El-Kholey KE, Elkomy A. Does the Drilling Technique for Implant Site Preparation Enhance Implant Success in Low-Density Bone? A Systematic Review. Implant Dent. 2019 Oct;28(5):500-509. Pubmed PMID: 31205268.

[11]. Peńarrocha M, Pérez H, Garciá A, Guarinos J. Benign paroxysmal positional vertigo as a complication of osteotome expansion of the maxillary alveolar ridge. J Oral Maxillofac Surg. 2001 Jan;59(1):106-7. Pubmed PMID: 11152180 .

[12]. Trisi P, Berardini M, Falco A, Podaliri Vulpiani M. New Osseodensification Implant Site Preparation Method to Increase Bone Density in Low-Density Bone: In Vivo Evaluation in Sheep. Implant Dent. 2016 Feb;25(1):24-31. Pubmed PMID: 26584202.

[13]. Blanco J, Suárez J, Novio S, Villaverde G, Ramos I, Segade LA. Histomorphometric assessment in human cadavers of the peri-implant bone density in maxillary tuberosity following implant placement using osteotome and conventional techniques. Clin Oral Implants Res. 2008 May;19(5):505-10. Pubmed PMID: 18371096.

[14]. Mazzocco F, Nart J, Cheung WS, Griffin TJ. Prospective evaluation of the use of motorized ridge expanders in guided bone regeneration for future implant sites. Int J Periodontics Restorative Dent. 2011 Sep-Oct;31(5):547-54. Pubmed PMID: 21845249.

[15]. Vercellotti T. Piezoelectric surgery in implantology: a case report--a new piezoelectric ridge expansion technique. Int J Periodontics Restorative Dent. 2000 Aug;20(4):358-65.Pubmed PMID: 11203575.

[16]. Kim YK, Kim SG. Horizontal ridge expansion and implant placement using screws: a report of two cases. J Korean Assoc Oral Maxillofac Surg. 2014 Oct;40(5):233-9. Pubmed PMID: 25368836.

[17]. Siddiqui AA, Sosovicka M. Lateral bone condensing and expansion for placement of endosseous dental implants: a new technique. J Oral Implantol. 2006;32(2):87-94. doi: 10.1563/786.1.Pubmed PMID: 16704111. 
[18]. Huwais S. Fluted osteotome and surgical method for use. US2013/0004918. US Patent Application. 2013 Jan;3.

[19]. Huwais S, Meyer EG. A Novel Osseous Densification Approach in Implant Osteotomy Preparation to Increase Biomechanical Primary Stability, Bone Mineral Density, and Bone-to-Implant Contact. Int J Oral Maxillofac Implants. 2017 Jan/Feb;32(1):27-36. Pubmed PMID: 27741329.

[20]. Huwais S. Autografting osteotome. Geneva, Switzerland: World Intellectual Property Organization Publication. 2014 May 22.

[21]. Huwais S, Meyer E. Osseodensification: A novel approach in implant o preparation to increase primary stability, bone mineral density and bone to implant contact. Int J Oral Maxillofac Implants. 2015.

[22]. Lahens B, Neiva R, Tovar N, Alifarag AM, Jimbo R, Bonfante EA, et al. Biomechanical and histologic basis of osseodensification drilling for endosteal implant placement in low density bone. An experimental study in sheep. J Mech Behav Biomed Mater. 2016 Oct;63:56-65. Pubmed PMID: 27341291

[23]. Witek L, Alifarag AM, Tovar N, Lopez CD, Gil LF, Gorbonosov M, Hannan K, Neiva R, Coelho PG. Osteogenic parameters surrounding trabecular tantalum metal implants in osteotomies prepared via osseodensification drilling. Med Oral Patol Oral Cir Bucal. 2019 Nov 1;24(6):e764-e769. Pubmed PMID: 31655837.

[24]. Sultana A, Makkar S, Saxena D, Wadhawan A, Kusum CK. To compare the stability and crestal bone loss of implants placed using osseodensification and traditional drilling protocol: A clinicoradiographical study. J Indian Prosthodont Soc. 2020 Jan-Mar;20(1):45-51. Pubmed PMID: 32089598.
[25]. Johnson EC, Huwais S, Olin PS. Osseodensification increases primary implant stability and maintains high ISQ values during first six weeks of healing. InPresentation at th e American Academy of Implant Dentistry 63rd Annual Meeting 2014.

[26]. Lahens B, Lopez CD, Neiva RF, Bowers MM, Jimbo R, Bonfante EA, et al. The effect of osseodensification drilling for endosteal implants with different surface treatments: A study in sheep. J Biomed Mater Res B Appl Biomater. 2019 Apr;107(3):615-623. Pubmed PMID: 30080320.

[27]. Slete FB, Olin P, Prasad H. Histomorphometric Comparison of 3 Osteotomy Techniques. Implant Dent. 2018 Aug;27(4):424-428. PubmedPMID: 29762184.

[28]. Gaspar J, Esteves T, Gaspar R, Rua J, Joăo Mendes J. Osseodensification for implant site preparation in the maxilla-a prospective study of 97 implants. Clinical Oral Implants Research. 2018 Oct;29:163-.

[29]. Chan HL, Fu JH, Koticha T, Benavides E, Wang HL. Ridge width gain with screw spreaders: a cadaver study. Implant Dent. 2013 Oct;22(5):552-8. Pubmed PMID: 24013399.

[30]. Kao DW, Fiorellini JP. Comparison of ridge expansion and ridge splitting techniques for narrow alveolar ridge in a Swine cadaver model. Int J Periodontics Restorative Dent. 2015 May-Jun;35(3):e44-9. Pubmed PMID: 25909532.

[31]. Cortes AR, Cortes DN. Nontraumatic bone expansion for immediate dental implant placement: an analysis of 21 cases. Implant Dent. 2010 Apr;19(2):92-7. Pubmed PMID:20386211. 